\title{
Long term outcomes of transcatheter aortic valve implantation (TAVI): a systematic review of 5-year survival and beyond
}

\author{
Adam Chakos ${ }^{1}$, Ashley Wilson-Smith ${ }^{1}$, Sameer Arora ${ }^{2}$, Tom C. Nguyen ${ }^{3}$, Abhijeet Dhoble ${ }^{4}$, Giuseppe \\ Tarantini $^{5}$, Matthias Thielmann ${ }^{6}$, John P. Vavalle ${ }^{2}$, Daniel Wendt ${ }^{6}$, Tristan D. Yan ${ }^{1,7}$, David H. Tian ${ }^{1,8}$ \\ ${ }^{1}$ The Collaborative Research (CORE) Group, Macquarie University, Sydney, Australia; ${ }^{2}$ Division of Cardiology, University of North Carolina, \\ Chapel Hill, NC, USA; ${ }^{3}$ Department of Cardiothoracic and Vascular Surgery, University of Texas Medical School at Houston, Memorial Hermann \\ Hospital - Heart and Vascular Institute, Houston, TX, USA; ${ }^{4}$ Division of Cardiology, University of Texas Health Science Center, Houston, Houston, \\ TX, USA; ${ }^{5}$ Department of Cardiac, Thoracic and Vascular Sciences, University Padua, Padua, Italy; ${ }^{6}$ Department of Thoracic and Cardiovascular \\ Surgery, West-German Heart and Vascular Center Essen, University Duisburg-Essen, Duisburg, Germany; ${ }^{7}$ Department of Cardiothoracic Surgery, \\ Royal Prince Alfred Hospital, Sydney, Australia; ${ }^{8}$ Royal North Shore Hospital, Sydney, Australia \\ Correspondence to: Dr. David Tian. The Collaborative Research (CORE) Group, Macquarie University, Sydney, Australia. Email: drdavidtian@gmail.com.
}

Background: Transcatheter aortic valve implantation/replacement (TAVI/TAVR) is becoming more frequently used to treat aortic stenosis (AS), with increasing push for the procedure in lower risk patients. Numerous randomized controlled trials have demonstrated that TAVI offers a suitable alternative to the current gold standard of surgical aortic valve replacement (SAVR) in terms of short-term outcomes. The present review evaluates long-term outcomes following TAVI procedures.

Methods: Literature search using three electronic databases was performed up to June 2017. Studies which included 20 or more patients undergoing TAVI procedures, either as a stand-alone or concomitant procedure and with a follow-up of at least 5 years, were included in the present review. Literature search and data extraction were performed by two independent researchers. Digitized survival data were extracted from Kaplan-Meier curves in order to re-create the original patient data using an iterative algorithm and subsequently aggregated for analysis.

Results: Thirty-one studies were included in the present analysis, with a total of 13,857 patients. Two studies were national registries, eight were multi-institutional collaborations and the remainder were institutional series. Overall, $45.7 \%$ of patients were male, with mean age of $81.5 \pm 7.0$ years. Where reported, the mean Logistic EuroSCORE (LES) was 22.1 \pm 13.7 and the mean Society of Thoracic Surgeons (STS) score was $9.2 \pm 6.6$. The pooled analysis found 30-day mortality, cerebrovascular accidents, acute kidney injury (AKI) and requirement for permanent pacemaker (PPM) implantation to be $8.4 \%, 2.8 \%, 14.4 \%$, and $13.4 \%$, respectively. Aggregated survival at 1-, 2-, 3-, 5- and 7-year were 83\%, 75\%, 65\%, 48\% and 28\%, respectively.

Conclusions: The present systematic review identified acceptable long-term survival results for TAVI procedures in an elderly population. Extended follow-up is required to assess long-term outcomes following TAVI, particularly before its application is extended into wider population groups.

Keywords: Transcatheter aortic valve implantation; TAVI; survival; long-term; systematic review

Submitted Sep 16, 2017. Accepted for publication Sep 24, 2017.

doi: $10.21037 /$ acs.2017.09.10

View this article at: http://dx.doi.org/10.21037/acs.2017.09.10 


\section{Introduction}

As Western populations age, the prevalence of aortic stenosis (AS) is gradually increasing (1). In a select population, surgical aortic valve replacement (SAVR) is precluded by patient frailty and other comorbidities (2). The availability of transcatheter aortic valve implantation/ replacement (TAVI/TAVR), pioneered in the early 2000s, has made a significant impact on survival for these patients (3-5). These early successes led to a number of trials, such as the PARTNER and US Pivotal trials, which compared TAVI, SAVR and standard treatment outcomes (Figure 1). As a result, TAVI is increasingly being considered as a less-invasive option for treatment of AS in younger and lower surgical risk patients, where SAVR is not necessarily contraindicated $(6,7)$, although this is not without controversy (8).

While the short-term outcomes of TAVI have been well explored, limited studies have examined longer term results $(9,10)$. Additionally, while much data has been published on SAVR survival beyond 5 years, there are relatively few studies (outside the Edwards and Medtronic trials) that present long-term, two-armed results with TAVI and SAVR. The present review aims to identify and analyze survival outcomes of studies which present 5-year of follow-up.

\section{Methods}

\section{Literature search}

Electronic searches were performed on Medline, Scopus and PubMed from dates of database inception to June 2017 using ("transcatheter aortic valve implantation" OR "transcatheter aortic valve replacement" OR "TAVI" OR "TAVR") AND ("survival" OR "long-term" OR "KaplanMeier"), either as keywords or MeSH headings. Records were systematically reviewed according to the inclusion and exclusion criteria by two independent authors (Adam Chakos, Ashley Wilson-Smith). A PRISMA diagram of the search process is presented in Figure S1.

\section{Inclusion/exclusion criteria}

Studies were included if 20 or more patients underwent TAVI (via any access approach and as a stand-alone or concomitant procedure), and where follow-up was for at least five years. Time-to-event data was required to be present in order to facilitate statistical analysis. NonEnglish studies, review articles, conference abstracts, editorials, letters, case reports and opinions were excluded. Only the most up-to-date study was included if duplicating studies were published for the same patient cohort.

\section{Quality assessment of included studies}

A modified quality appraisal schema, based on the Canadian National Institute of Health's Quality Assessment Tool for Case Series Studies, was used to evaluate all included studies (11). In short, studies were scored based on six main domains: clarity of objective, characteristics of the study population, description of the intervention, adequate outcome measures, suitable statistical analysis, and appropriate results/conclusions (quality is listed in Table S1). Studies were scored out of 16 points. Studies scoring 13-16 were categorized as high-quality, 10-12 medium-quality and below 10 were low-quality.

The primary outcome of interest is time-to-event survival data. Secondary outcomes of interest included short-term outcomes such 30-day mortality, 30-day stroke/ CVA, permanent pacemaker (PPM) implantation and acute kidney injury (AKI). Definitions from the Valve Academic Research Consortium (VARC)-2 consensus were used where appropriate (12). Logistic EuroSCORE (LES) was recorded in preference to additive EuroSCORE and EuroSCORE II since the former was replaced by the logistic model and the latter was not widely reported as it has only been in use since 2012.

\section{Statistical analysis}

Baseline patient data, risk factors, operative details and operative outcomes were extracted by two independent researchers. Kaplan-Meier curves were digitized and iteratively computed to generate individual patient data, using the algorithm from Guyot and colleagues (13). Censoring was assumed to be constant unless the particular curve had a long follow-up of only minimal patients (in which case, censoring was manually entered). The death event and censoring data for the entire cohort was pooled and an overall survival curves calculated according to the Kaplan-Meier method using MATLAB R2016a [Natick, Massachusetts, US (14)]. Survival was also compared to the general population by utilizing life tables obtained from government sources specific to the majority of patients within the included studies (15-17). Specifically, weighted survival (according to patient numbers) for Italy, UK, Germany, Canada, US and Spain were used, accounting for 
Publications with title/abstract containing any of TAVI, TAVR, Transcatheter aortic, Percutaneous aortic

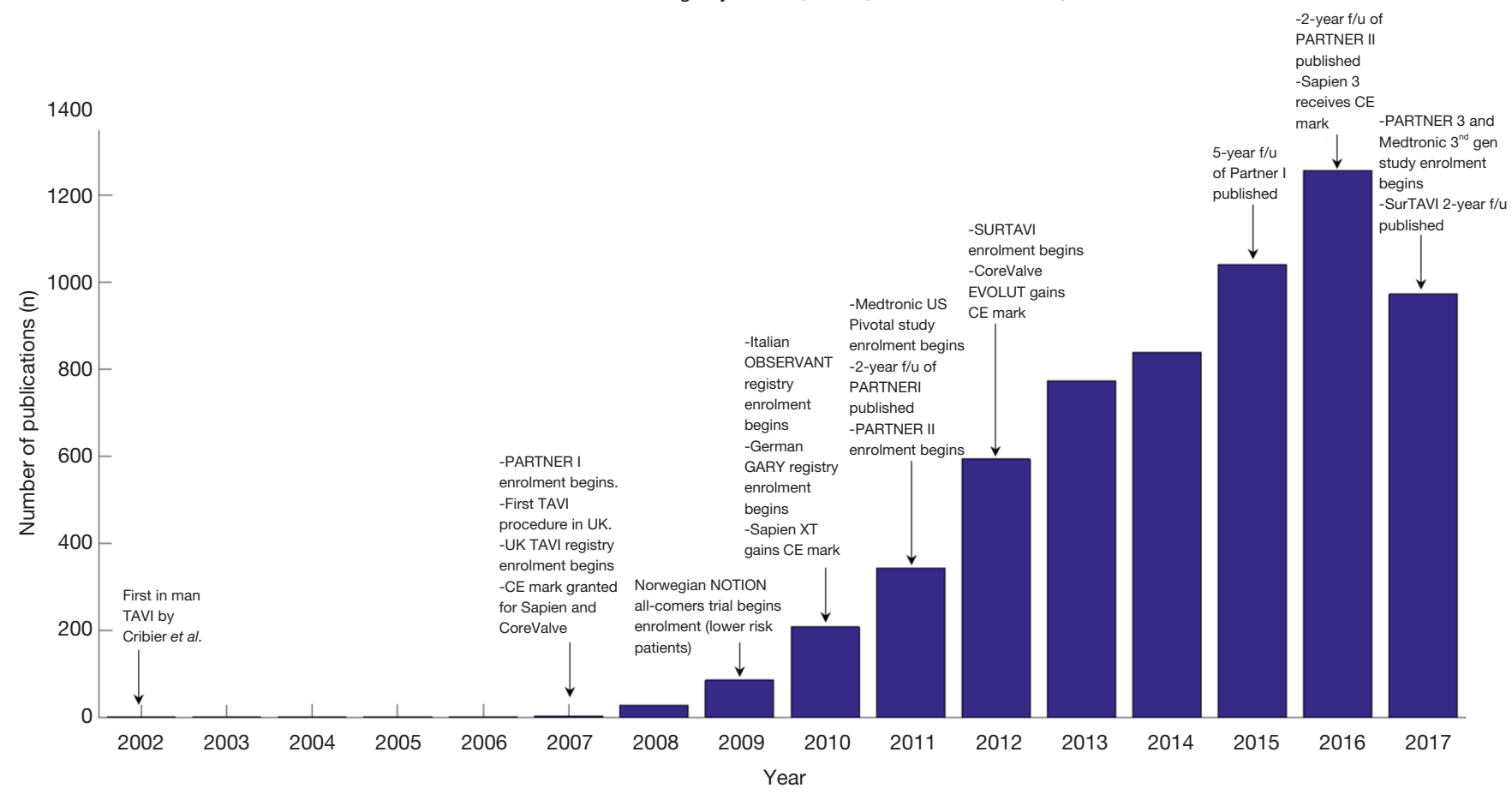

Figure 1 Timeline of publication rate annotated with significant events since the introduction of TAVI. Number of publications by year extracted from PubMed. TAVI, transcatheter aortic valve implantation; TAVR, transcatheter aortic valve replacement.

$93 \%$ of all included patients.

\section{Results}

Overall 5,194 records were identified in the literature search. Following application of the inclusion and exclusion criteria, 31 studies were included for analysis, with a total of 13,857 patients. The median number of patients per study was 120 (interquartile range 60-292) with median followup of 5 years (interquartile range 5-6 years, mean follow-up 5.6 years). These studies included 23 single-center studies $(6,10,18-38)$ and 8 multi-center studies (39-46), where 14 were retrospective and 15 had prospective enrolment. The studies were conducted in the UK, Italy, Germany, US, Canada, Spain, Israel, Denmark and Sweden. Seven studies were deemed high-quality studies, 19 as medium-quality and 5 as low-quality. Kaplan-Meier survival for patients in the three study groups was calculated and results are presented in Figure $S 2$.

The mean age for the entire cohort was $81.5 \pm 7.0$ years, with $45.7 \%$ males. Pre-operative LES was the most widely available risk statistic among included studies, reported for $91 \%$ of the total cohort, with a mean value of $22.1 \% \pm 13.7 \%$. Pre-operative Society of Thoracic Surgeons (STS) score was reported for $50 \%$ of the cohort at a mean risk value of $9.17 \% \pm 6.61 \%$. Baseline characteristics and comorbidities (such as hypertension, $\mathrm{LVEF} \%$, cardiac history and interventions) recorded across more than half of the included studies are summarized in Table 1 and fully detailed in Table $S 2$.

Multiple types of valves were used, which was reported by $84 \%$ of studies. For those studies which specified valve type, $64.7 \%$ of reported patients received an Edwards valve (Sapien, Sapien XT, Sapien 3), 33.5\% received a Medtronic valve (CoreValve, Evolut R) and $1.7 \%$ of patients received a different type (Lotus or JenaValve). Valve delivery approach was specified for $92 \%$ of included patients. Where specified, $68.5 \%$ of approaches were transfemoral, $34.8 \%$ were transapical, $2.6 \%$ were trans-subclavian and $1.9 \%$ were trans-aortic (and other) approach type.

Aggregated survival rates at 1-, 2-, 3-, 5-, and 7-year were $83 \%, 75 \%, 65 \%, 48 \%$, and $28 \%$, respectively. The overall survival curve derived from reconstructed individual patient data is shown in Figure 2. 


\begin{tabular}{|c|c|}
\hline Characteristics & Data \\
\hline Total patients (n) & 13,857 \\
\hline Males (\%) & $6,327(45.7 \%)$ \\
\hline Age (mean $\pm S D)$ & $81.5 \pm 7.0$ \\
\hline Logistic EuroSCORE (mean \pm SD) $\%$ & $22.1 \pm 13.7$ \\
\hline STS score $($ mean \pm SD) $\%$ & $9.17 \pm 6.61$ \\
\hline Hypertension & $81.7 \%(5,447 / 6,667)$ \\
\hline Diabetes mellitus & $28.2 \%(3,414 / 12,104)$ \\
\hline Dyslipidaemia & $61.9 \%(2,318 / 3,743)$ \\
\hline Peripheral vascular disease & $28.7 \%(3,571 / 12,440)$ \\
\hline Pre-operative LVEF (\%) & $53.5 \pm 15.1$ \\
\hline Pulmonary disease & $25.7 \%(3,243 / 12,605)$ \\
\hline Previous cerebrovascular accidents & $12.1 \%(1,539 / 12,704)$ \\
\hline Previous CABG & $22.0 \%(1,093 / 4,962)$ \\
\hline Previous percutaneous intervention & $22.2 \%(2,138 / 9,628)$ \\
\hline Previous myocardial infarction & $20.1 \%(2,253 / 11,184)$ \\
\hline Renal disease & $18.2 \%(2,191 / 12,019)$ \\
\hline History of atrial fibrillation & $26.0 \%(1,814 / 6,981)$ \\
\hline
\end{tabular}

Where applicable, data is reported as percentage and the fraction of the total surveyed for a particular comorbidity. SD, standard deviation; STS, Society of Thoracic Surgeons; LVEF, left ventricular ejection fraction; CABG, coronary artery bypass graft.

Patients were further grouped according to their LES as either moderate (LES $\leq 20)$ or high-risk (LES $>20)$ and the respective results are shown in Figure 3. Risk factors and outcomes reported in more than half of the included studies were included for analysis in this review - a summary is presented in Table 1. Kaplan-Meier curves generated for high-, medium-, and low-quality studies are presented in Figure S2.

Post-operative 30-day mortality was $8.4 \%(12,913$ patients). Other widely reported post-operative outcomes included incidence of 30-day cerebrovascular accident ( $2.8 \%$ of 10,881 patients), AKI ( $14.4 \%$ of 7,963 patients) and requirement for PPM implantation (13.4\% of 11,599 patients). Other operative and post-operative details were insufficiently presented to facilitate statistical analysis (Table S3).

\section{Discussion}

\section{TAVI trials, expanding indications and criticisms}

Since introduction in 2002, TAVI has been used at increasing rates, with over one-hundred thousand procedures performed worldwide (47). Much of the clinical outcomes have been captured in a range of trials and registries, including the Edwards-sponsored PARTNER trials, Medtronic-sponsored Pivotal and SURTAVI trials, UK TAVI registry (UK), GARY registry (Germany), OBSERVANT registry (Italy) and NOTION trial (Norway) (3,48-54).

In 2011, the seminal PARTNER IA and IB randomized controlled trials, using Edwards' balloon-expandable valve, established the non-inferiority of TAVI compared to SAVR and the superiority of TAVI compared to medical management (55). These favorable results energized TAVI advocates, with more studies subsequently commenced. The validation of the Edwards valve encouraged Medtronic to develop their model, with similarly favorable results from their Pivotal RCT subsequently published in 2014 (50). Both trials recruited high-risk patients (or non-surgical candidates in PARTNER IB), establishing the clinical legitimacy of utilizing TAVI in these patients $(34,56)$. Despite early differences in TAVI and SAVR outcomes seen in the PARTNER IA trial, at five-years these differences have dissipated. However, TAVI's higher rate of vascular complications and paravalvular leak persisted at five years, raising concerns. SAVR patients in PARTNER I had higher rates of major bleeding post-operatively and in the long term $(34,49,56,57)$.

Like PARTNER IA, the three-year follow-up of the US Pivotal trial (again with a $7.5 \%$ difference required for inferiority) found similar mortality between SAVR and TAVI, the same issues of vascular complications and valvular regurgitation (including para-valvular leak) and reported higher incidence of re-intervention in TAVI. SAVR patients in the Pivotal trial also had higher rates of major bleeding and AKI compared to TAVI. Unlike the Edwards valve, significant need for PPM implantation compared to SAVR persisted at three years in the CoreValve trial (58). Neither product demonstrated valvular deterioration at late follow-up, allaying early concerns regarding the longterm durability of TAVI valves due to device crimping for implantation (59).

Given the success demonstrated by the PARTNER I and US Pivotal trials, TAVI procedure rates increased 


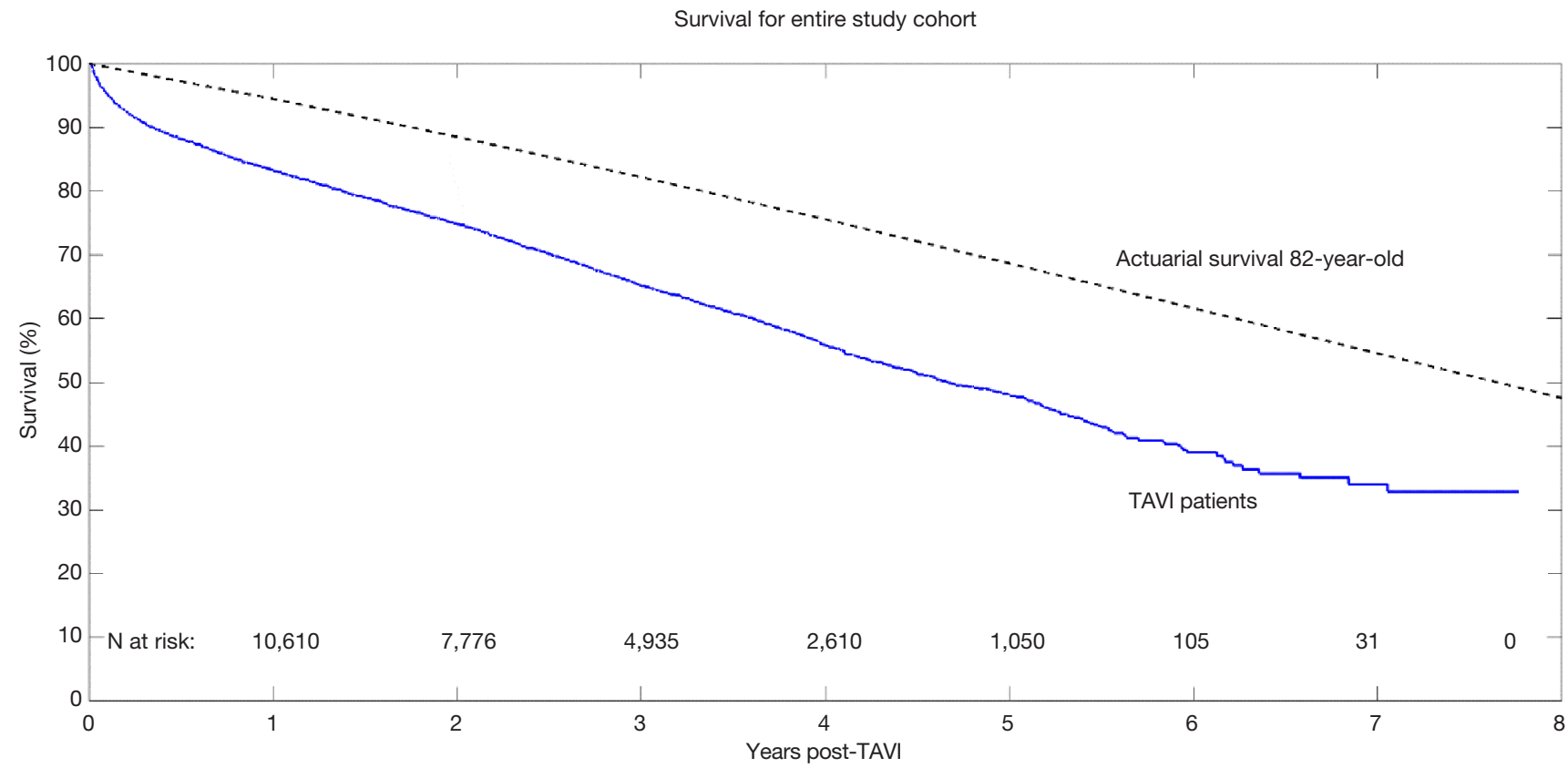

Figure 2 Aggregated long-term survival of patients receiving transcatheter aortic valve replacement. The expected survival curve for a general-population 82-year-old (calculated from the national life tables relevant to the included studies) is also plotted.

Survival by Logistic EuroSCORE cohort

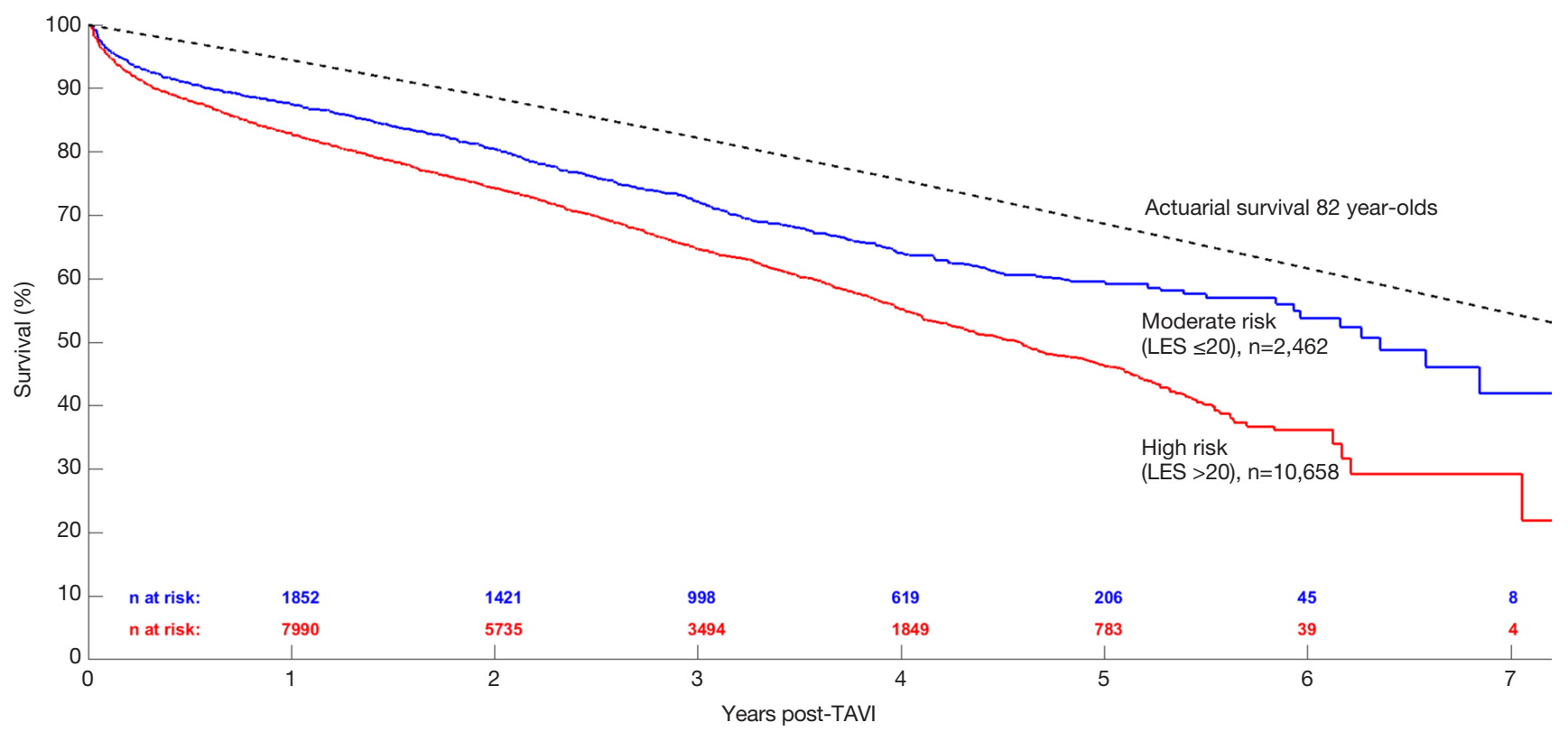

Figure 3 Long-term survival of patients receiving transcatheter aortic valve replacement, stratified according to high risk (logistic EuroSCORE $>20$, in red) or moderate risk (logistic EuroSCORE $\leq 20$, in blue). LES, logistic EuroSCORE. 
and began to be expanded to intermediate-risk cohorts by practitioners. The development of the newer generation Edwards (Sapien XT) and Medtronic (CoreValve Evolut $\mathrm{R})$ devices, along with the need to validate results in lowerrisk cohorts formed the basis for the PARTNER II and SURTAVI trials (Edwards and Medtronic, respectively), which examined patients with STS operative risk scores up to $8 \%$ (PARTNER II) and 15\% (SURTAVI) and enrolled more than twice the number of patients as the original Edwards and Medtronic trials. The mean STS scores in PARTNER II and SURTAVI were approximately $5.8 \% \pm 2.0 \%$ and $4.5 \% \pm 1.6 \%$, respectively $(49,51)$. This new wave of RCTs (now in moderate-risk patients) again established the short-term non-inferiority of TAVI compared to SAVR. However, the same issues of vascular complications, paravalvular leak and requirement for reintervention persisted in both Edwards and Medtronic trials (along with continued high rates of post-operative PPM in the CoreValve trial) $(49,51)$.

The NOTION trial in Norway also examined TAVI mortality in lower risk groups by virtue of its "all comers" nature. That RCT used the same 1:1 randomization for 280 patients receiving TAVI and SAVR and patients had a mean STS score of $3.0 \% \pm 1.7 \%$. The CoreValve was used and like the US Pivotal and SURTAVI trials, no statistically significant difference in mortality, stroke, or MI at 2 years between methods was found. Complications with respect to TAVI and SAVR were the same as the Pivotal and SURTAVI trials $(52,60,61)$.

Results of the PARTNER II trial raised concern over whether the findings of these RCTs reflect real-world outcomes, and whether it can potentially introduce bias in favor of TAVI. Some criticism of the PARTNER II trial raised concerns that treatment in the SAVR arm was not representative of current surgical practices and included undetailed concomitant interventions, although $15 \%$ of the SAVR cohort did undergo contemporary SAVR with a minimally invasive approach. However, it should be noted that the SAVR cohort also included patients that underwent concomitant mitral or tricuspid repair or coronary grafting (62).

A new generation of Edwards and Medtronic valves have now been launched (Sapien 3 and EVOLUT R, respectively) and the PARTNER 3 and US clinical trial NCT02701283 RCTs are presently recruiting to investigate their use in low operative mortality risk patients (STS $<4 \%$ for PARTNER 3, risk of mortality $<3 \%$ at 30 days for Medtronic RCT) $(63,64)$. Earlier studies also studied TAVI beyond the context of calcific AS, in pure aortic regurgitation patients $(65,66)$, bicuspid aortic valve and (as in a number of our included studies) valve-in-valve for both redo-TAVI or SAVR $(6,25,32,67,68)$.

TAVI is undoubtedly growing in usage across the world and as the results of these newer generation trials become available and potentially address earlier concerns, TAVI will inevitably be applied in a broader context to lower risk patients. Although national registries such as the UK TAVI trial report minimal "EuroSCORE creep" with time, later follow up from the recent Edwards and Medtronic trials showing durability and sustained favorable outcomes (as the earlier trials demonstrated) will likely lead to wider adoption in lower-risk cohorts and a noticeable risk score creep (69).

\section{Cost effectiveness of TAVI}

In addition to demonstrating the clinical effectiveness of TAVI, much has been published on its cost-effectiveness and financial sustainability for widespread adoption. These studies have used methods such as incremental cost effectiveness ratio (ICER), decision-analytic and Markov models to compare TAVI to SAVR and standard treatment. Analysis in the context of a government health system (the UK NHS) using data from the PARTNER I trials and extrapolated into the future calculated TAVI to cost anywhere from 2-5 times that of medical management $(70,71)$ but highlighted that TAVI achieves markedly better survival outcomes. Quality-adjusted life-years (QALY) analysis of PARTNER I and other national registries demonstrated that TAVI still fell within the cost limits set by the NICE guidelines used under the NHS and thus, is a suitable (and superior) treatment to medical management in the case of inoperable AS (70-73).

While TAVI has been evaluated as cost-effective in patients who are not candidates for surgery, it has yet to be shown to be financially sustainable in high-risk patients who can undergo a much more economical surgical AVR procedure. A significant driver of the cost-difference between SAVR and TAVI is the high device cost compared to surgical valves (74). When the cost of the device is discounted from the analysis, TAVI becomes comparable to SAVR, owing particularly to the reduced intensive care unit and hospital stay required for TAVI (42). It has also been noted that TAVI requires more extensive diagnostic workup (2), which may further offset the benefit of reduced hospital stay. Additionally, it is not clear whether all cost analyses accounted for costs associated with the higher reintervention and re-admission rates of TAVI compared to 
SAVR. However, Freeman and colleagues found in their analysis that when re-intervention and re-admission rates were considered, the cost per QALY for TAVI remained below the NICE threshold for coverage under the NHS, highlighting the potential long-term economic benefit of TAVI (73).

\section{Long-term outcomes}

A key factor in adoption of any new surgical procedure or device is its long-term efficacy. While the short-term results have been well studied, limited data exists regarding long-term outcomes following TAVI. The present review of nearly 14,000 cases found survival at 5 years to be $48 \%$. When compared against the actuarial survival of 82 -yearold, the aggregated results demonstrate poorer survival outcomes and a marginally worse Kaplan-Meier rate (after the initial attrition in the first year post-operatively). Mack and colleagues followed a small cohort of nonagenarians receiving TAVI in the US and found that their survival at 5 years to be approximately $30 \%$, which was consistent with the expected age- and sex-matched actuarial survival in this elderly cohort (33).

\section{Limitations}

Firstly, a wide range of TAVI models and generations were included in the present analysis, which could not be accounted for. Secondly, the data presented in this review included series from the early TAVI era, where the learning curve associated with the uptake of this technology could have influenced these results. The likely evolution of patient selection, the procedure itself, and post-operative management is likely to have had an effect on survival outcomes in contemporary TAVI applications. It is also acknowledged that the heterogeneity in patient selection and procedural variations may have also affected outcomes. Finally, the method used to re-construct patient data from Kaplan-Meier survival curves assumed constant censoring and this may have impacted on the computed patient data.

\section{Conclusions}

It is widely anticipated that as results of newer generation device trials become available, TAVI will be applied in a broader context to lower risk patients. As TAVI registries continue to mature and grow, particularly all-comers registries like the UK TAVI registry, a clear case profile for TAVI may be brought in to focus. Additionally, as newer valve designs and device manufacturers enter the market, the economic case for TAVI will undoubtedly improve. However, future cost analyses must be included the procedural workup and long-term follow-up treatments. Despite the aggregated results identified in the present analysis, it is abundantly clear that extended data is required to clarify the long-term outcomes of TAVI.

\section{Expert opinion 1 (Sameer Arora, John P. Vavalle)}

In this study, Chakos and colleagues report an exhaustive aggregation of studies with reported follow-up of 5 years or more after TAVR. The aggregated survival at 5- and 7-year follow-up after TAVR was $48 \%$ and $28 \%$, respectively. The study population largely represents a high-surgical risk category with more than $80 \%$ of the patients at highsurgical-risk with the mean STS $>9$. Additionally, most of the included studies were of initial experiences of TAVR, and therefore, do not take into consideration the improvements in prostheses and operator experiences in recent years. However, this study provides a benchmark for the more recent TAVR experiences and will help us to evaluate if improvements in prostheses performance and operator experiences has led to improvement in overall outcomes, which we expect it has.

In the US, TAVR is now recommended for patients with severe AS and high or inoperable-surgical risk, and is an alternative to surgery for intermediate-risk patients. Although the authors found a reduced survival for postTAVR patients when compared to a general population of similar mean age, this does not take into account the comorbidities that made the patient high or extreme risk for surgery. This highlights the overall morbidity of many of these patients undergoing TAVR, and supports the notion that a less invasive approach is favored for this group.

This study now helps set the stage for the next frontier of TAVR-low surgical risk patients. As we move towards an "all-comers" treatment paradigm for TAVR, there are several important unanswered questions. These include durability of the valve, higher rates of PPM, paravalvular leak, and long-term survival. As we await the results of the randomized trials of low risk patients, this study provides further support to pushing the envelope towards low risk. One thing is certain, TAVR is here to stay, and its rapid growth will only accelerate; however, we must use caution to not expand its use to low risk patients until we are certain of the long-term outcomes. 


\section{Expert opinion 2: a step back to reexamine the evidence? (Tom C. Nguyen, Abhijeet Dhoble)}

In the study, Chakos and colleagues present data on TAVI survival from 31 studies involving 13,857 patients. The authors found that the aggregated survival rates at 1-, $2-, 3-, 5-$, and 7 -year were $83 \%, 75 \%, 65 \%, 48 \%$, and $28 \%$, respectively. The mean age of the study population was 82 years. When compared to the actuarial survival of an 82 -year-old healthy person, survival post-TAVI was poorer. This study represents the first systematic review of TAVI investigating long-term actuarial survival. The authors should be congratulated for their novel approach in exploring TAVI durability compared against an actuarial cohort. The authors further stratified patients into intermediate and high-risk categories. Expectedly, high risk patients experienced worse survival. These findings raise a question on widespread global acceptance of TAVI. It is to be noted that the present study included only registries and studies with longer term follow up, which included mostly high-risk patients with mean STS score of $9.17 \% \pm 6.61 \%$. Some of the patients included were treated as early as 2005 , likely with the 1 st generation TAVI devices.

The PARTNER 1B (inoperable) study that included patients with mean age of 83 years and mean STS of $11.7 \%$ showed 5-year mortality of $93.6 \%$ in medically managed patients, and $71.8 \%$ in TAVI group (56). The risk of death at 5 years was $67.8 \%$ in the TAVI group compared with $62.4 \%$ in the SAVR group (hazard ratio $1.04, \mathrm{P}=0.76$ ) in the PARTNER 1A (high risk) cohort (34). Additionally, a Mayo Clinic study showed that the asymptomatic patients with severe AS has 5-year mortality of $43 \%$ irrespective to whether they undergo SAVR. The same study also found that the 1-, 2-, and 5-year probabilities of remaining free of surgery or cardiac death were $80 \%, 63 \%$ and $25 \%$, respectively (75). These high-quality data suggest that AS is a potentially fatal disease if left untreated, and mortality remains high even if the patient is treated.

The findings of this study should raise the question of global TAVI acceptance without better quality data supporting durability. This is particularly true as TAVI evolves into intermediate and lower risk cohorts where durability data is scant. Longer term follow-up data from randomized intermediate and low risk PARTNER and CoreValve trials will potentially shed light on the durability of this technology. Until then, it is prudent to step back and continue to actively reexamine the evidence for TAVI.

\section{Expert opinion 3: taking two birds (durability and lower risk) with one stone (younger patients): next TAVI challenge (Giuseppe Tarantini)}

TAVR has rapidly become the treatment of choice for AS patients at extreme or high surgical risk, and the results of recent randomized trials have now broadened TAVR indications to lower risk subjects. Nevertheless, the common risk scores used in clinical practice are accurate to predict the outcome of patients treated surgically but not by TAVI (1). The point is why? Unlike surgical series (76), in TAVI series, the progressive decrease in mean risk score value across studies is not paralleled by a significant change in TAVR patients mean age, which steadily remained above 80 years. Data on younger patients are lacking and is difficult to find. In ongoing trials, the entry criteria remain with the heart team. Considering the previously reported disconnection between risk and age-I would expect to see data still related on patients older than 80 years.

Granted that, in our opinion, future TAVR research should concentrate on outcomes of younger patients. Performing TAVR in $<75$-year-old subjects will allow us to get the eagerly awaited data on prostheses durability, which remains the last strong argument against transcatheter therapy. This, of course, has to be done by means of randomized controlled trials against SAVR. However, in order to compete with the excellent results of SAVR in younger patients, TAVR has to guarantee a 30 -day mortality and stroke-rate around $1 \%$, major vascular complications rate $<3 \%$, and new $\mathrm{PM}$ implantation rate $<10 \%$. Furthermore, the hemodynamic performance of transcatheter devices in the setting of bicuspid AS has to improve (especially in terms of paravalvular leakage), since this anatomical finding will dramatically increase in frequency as we move to younger subjects.

TAVR has walked a long and exciting road since the first patient was treated in 2002, but there is still much to walk before we can safely and effectively offer transcatheter therapy to every AS patient.

\section{Expert opinion 4: 'times they are a-changin' (Matthias Thielmann, Daniel Wendt)}

Since TAVI has been introduced in 2002 into clinical practice, it has successfully evolved (with more than 100,000 procedures worldwide) to become a main-stream 
therapeutic option for symptomatic patients with severe AS. Initial evidence for TAVI came from first industrysponsored clinical trials but also from several national registries considering patients who were deemed to be inoperable or non-surgical candidates as well as patients presenting with a high surgical risk. With growing experience, further developed TAVI devices and further evidence from more recent trials (although most of them still industry-initiated, -sponsored, and -controlled), the indication has and is going to shift to lower risk patients.

Aside from the euphoria around TAVI regarding its application and criticisms, the question of TAVI longterm performance and outcomes is as yet uncertain. First insights from initial randomized trials and registries were quite limited in the face of patient's age and comorbidities and present long-term data are still rare and limited in their validity and interpretation. Nevertheless, there is certainly no doubt that long-term performance and outcomes are and will become the major determinant for TAVI treatmentparticularly in the lower risk, younger patients.

The present systematic review by Chakos and colleges of long-term outcomes of TAVI encompassing nearly 14,000 TAVI patients derived from 31 worldwide studies and national registries showed an aggregated 5 -year survival of $48 \%$ and a 7 -year survival of $28 \%$. This is the first systematic review of TAVI that has been investigated on long-term survival in this fashion. By comparing the actuarial survival against an age-matched population, survival post-TAVI was significantly inferior, particularly in the high-risk group. This is at first not unexpected given the patient population and comorbidities. Nevertheless, when comparing the longterm survival of SAVR with a similar age- and gendermatched population, Wendt and colleges (77) could clearly demonstrate a non-inferiority of SAVR over a similar longterm period.

Of important note, not only long-term survival, but also quality of life, incidence of repeat intervention rate, transvalvular gradients, prosthesis valve areas, and structural valve deterioration over a long-term follow-up are major important determinants which will play a key role when younger and lower risk patients are going to be considered for a TAVI treatment instead of SAVR. Therefore, much longer and lager follow-up studies are needed to objectively judge whether TAVI is superior to SAVR and should therefore be offered and recommended to a younger and lower risk patient clientele.

'And the first one now will later be last-for the times they are a-changin'-freely adapted from Bob Dylan.

\section{Acknowledgements}

None.

\section{Footnote}

Conflicts of Interest: The authors have no conflicts of interest to declare.

\section{References}

1. Orvin K, Assali A, Vaknin-Assa H, et al. Efficacy and Safety of Transcatheter Aortic Valve Implantation in Aortic Stenosis Patients With Extreme Age. J Invasive Cardiol 2015;27:475-80.

2. Cao C, Liou KP, Pathan FK, et al. Transcatheter Aortic Valve Implantation versus Surgical Aortic Valve Replacement: Meta-Analysis of Clinical Outcomes and Cost-Effectiveness. Curr Pharm Des 2016;22:1965-77.

3. Beckmann A, Hamm C, Figulla HR, et al. The German Aortic Valve Registry (GARY): a nationwide registry for patients undergoing invasive therapy for severe aortic valve stenosis. Thorac Cardiovasc Surg 2012;60:319-25.

4. Zahn R, Gerckens U, Grube E, et al. Transcatheter aortic valve implantation: first results from a multi-centre realworld registry. Eur Heart J 2011;32:198-204.

5. Cribier A, Eltchaninoff $\mathrm{H}$, Bash A, et al. Percutaneous transcatheter implantation of an aortic valve prosthesis for calcific aortic stenosis. Circulation 2002;106:3006-8.

6. D'Onofrio A, Facchin M, Besola L, et al. Intermediate Clinical and Hemodynamic Outcomes After Transcatheter Aortic Valve Implantation. Ann Thorac Surg 2016;101:881-8; Dissicussion 888.

7. Webb J, Cribier A. Percutaneous transarterial aortic valve implantation: what do we know? Eur Heart J 2011;32:140-7.

8. Van Brabandt H, Neyt M, Hulstaert F. Transcatheter aortic valve implantation (TAVI): risky and costly. BMJ 2012;345:e4710.

9. Avanzas P, Pascual I, Munoz-Garcia AJ, et al. Long-term Follow-up of Patients With Severe Aortic Stenosis Treated With a Self-expanding Prosthesis. Rev Esp Cardiol (Engl Ed) 2017;70:247-53 .

10. Escárcega RO, Lipinski MJ, Baker NC, et al. Analysis of long-term survival following transcatheter aortic valve implantation from a single high-volume center. Am J Cardiol 2015;116:256-63.

11. Institute of Health Economics. Quality Appraisal of Case Series Studies Checklist: Institute of Health Economics 
(IHE) Edmonton (AB): Institute of Health Economics 2014. Available online: http://www.ihe.ca/researchprograms/rmd/cssqac/cssqac-about

12. Kappetein AP, Head SJ, Généreux P, et al. Updated standardized endpoint definitions for transcatheter aortic valve implantation: the Valve Academic Research Consortium-2 consensus document. J Thorac Cardiovasc Surg 2013;145:6-23.

13. Guyot P, Ades AE, Ouwens MJ, et al. Enhanced secondary analysis of survival data: reconstructing the data from published Kaplan-Meier survival curves. BMC Med Res Methodol 2012;12:9.

14. The MathWorks, Inc. MATLAB R2016a. 1994-2017. The MathWorks, Inc. Available online: https://au.mathworks. com/help/stats/kaplan-meier-methods.html

15. Istat INIoS. Life Tables, Age (2015). Istat - Istituto nazionale di statistica, Italian National Institute of Statistics. Accessed August 2017. Available online: http:// dati.istat.it/?lang=en\&SubSessionId=69f1abe2-7797-4632$908 \mathrm{c}-\mathrm{fb} 264 \mathrm{c} 3 \mathrm{a} 606 \mathrm{f} \&$ themetreeid $=-200 \#$

16. Office of National Statistics-UK. National Life Tables - England 2013-15. Office of National Statistics, United Kingdom. Available online: https:// www.ons.gov.uk/peoplepopulationandcommunity/ birthsdeathsandmarriages/lifeexpectancies/datasets/nation allifetablesenglandreferencetables

17. The Human Life-Table Database. Jointly published by Max Planck Institute for Demographic Research (Germany), UC Berkeley (US), Institut national d'études démographiques (France), 2007. Accessed August 2017. Available online: http://lifetable.de/

18. Barone-Rochette G, Piérard S, De Meester de Ravenstein $\mathrm{C}$, et al. Prognostic significance of LGE by CMR in aortic stenosis patients undergoing valve replacement. J Am Coll Cardiol 2014;64:144-54.

19. Bouleti C, Chauvet M, Franchineau G, et al. The impact of the development of transcatheter aortic valve implantation on the management of severe aortic stenosis in high-risk patients: treatment strategies and outcome. Eur J Cardiothorac Surg 2017;51:80-8.

20. Buzzatti N, Castiglioni A, Agricola E, et al. Fiveyear evolution of mild aortic regurgitation following transcatheter aortic valve implantation: early insights from a single-centre experience. Interact Cardiovasc Thorac Surg 2017;25:75-82.

21. Chen J, Nawaz N, Fox Z, et al. Echocardiographic determinants of $\mathrm{LV}$ functional improvement after transcatheter aortic valve replacement. Catheter
Cardiovasc Interv 2016;87:1164-72.

22. Codner P, Orvin K, Assali A, et al. Long-Term Outcomes for Patients With Severe Symptomatic Aortic Stenosis Treated With Transcatheter Aortic Valve Implantation. Am J Cardiol 2015;116:1391-8.

23. Engborg J, Riechel-Sarup C, Gerke O, et al. Effect of permanent pacemaker on mortality after transcatheter aortic valve replacement. Scand Cardiovasc J 2017;51:40-6.

24. Gotzmann M, Knoop H, Ewers A, et al. Impact of lung diseases on morbidity and mortality after transcatheter aortic valve implantation: insights from spirometry and body plethysmography. Am Heart J 2015;170:837-42.e1.

25. Huded CP, Youmans QR, Puthumana JJ, et al. Lack of Association Between Extracranial Carotid and Vertebral Artery Disease and Stroke After Transcatheter Aortic Valve Replacement. Can J Cardiol 2016;32:1419-24.

26. Johansson M, Nozohoor S, Bjursten H, et al. Late survival and heart failure after transcatheter aortic valve implantation. Asian Cardiovasc Thorac Ann 2016;24:318-25.

27. Løgstrup BB, Andersen HR, Thuesen L, et al. Left ventricular global systolic longitudinal deformation and prognosis 1 year after femoral and apical transcatheter aortic valve implantation. J Am Soc Echocardiogr 2013;26:246-54.

28. López-Aguilera J, Segura Saint-Gerons JM, Sánchez Fernández J, et al. Long-term clinical impact of permanent cardiac pacing after transcatheter aortic valve implantation with the CoreValve prosthesis: a single center experience. Europace 2017. [Epub ahead of print].

29. Muñoz-García AJ, Munoz-Garcia E, Jimenez-Navarro MF, et al. Clinical impact of acute kidney injury on shortand long-term outcomes after transcatheter aortic valve implantation with the CoreValve prosthesis. J Cardiol 2015;66:46-9.

30. Penkalla A, Pasic M, Drews T, et al. Transcatheter aortic valve implantation combined with elective coronary artery stenting: a simultaneous approachdagger. Eur J Cardiothorac Surg 2015;47:1083-9.

31. Pilgrim T, Englberger L, Rothenbuhler M, et al. Longterm outcome of elderly patients with severe aortic stenosis as a function of treatment modality. Heart 2015;101:30-6.

32. Ruparelia N, Latib A, Buzzatti N, et al. Long-Term Outcomes After Transcatheter Aortic Valve Implantation from a Single High-Volume Center (The Milan Experience). Am J Cardiol 2016;117:813-9.

33. Salinas P, Moreno R, Calvo L, et al. Long-term Follow-up After Transcatheter Aortic Valve Implantation for Severe Aortic Stenosis. Rev Esp Cardiol (Engl Ed) 2016;69:37-44. 
34. Santarpino G, Pfeiffer S, Jessl J, et al. Clinical Outcome and Cost Analysis of Sutureless Versus Transcatheter Aortic Valve Implantation With Propensity Score Matching Analysis. Am J Cardiol 2015;116:1737-43.

35. Schymik G, Würth A, Bramlage P, et al. Long-term results of transapical versus transfemoral TAVI in a real world population of 1000 patients with severe symptomatic aortic stenosis. Circ Cardiovasc Interv 2014;8.

36. Toggweiler S, Humphries KH, Lee M, et al. 5-year outcome after transcatheter aortic valve implantation. J Am Coll Cardiol 2013;61:413-9.

37. Unbehaun A, Pasic M, Buz S, et al. Transapical aortic valve implantation in patients with poor left ventricular function and cardiogenic shock. J Thorac Cardiovasc Surg 2014;148:2877-82.e1.

38. Ye J, Cheung A, Yamashita M, et al. Transcatheter Aortic and Mitral Valve-in-Valve Implantation for Failed Surgical Bioprosthetic Valves: An 8-Year Single-Center Experience. JACC Cardiovasc Interv 2015;8:1735-44.

39. Barbanti M, Petronio AS, Ettori F, et al. 5-Year Outcomes After Transcatheter Aortic Valve Implantation With CoreValve Prosthesis. JACC Cardiovasc Interv 2015;8:1084-91.

40. Brunner NW, Yue SF, Stub D, et al. The prognostic importance of the diastolic pulmonary gradient, transpulmonary gradient, and pulmonary vascular resistance in patients undergoing transcatheter aortic valve replacement. Catheter Cardiovasc Interv 2017. [Epub ahead of print].

41. D'Onofrio A, Tarja E, Besola L, et al. Early and Midterm Clinical and Hemodynamic Outcomes of Transcatheter Valve-in-Valve Implantation: Results From a Multicenter Experience. Ann Thorac Surg 2016;102:1966-73.

42. Ludman PF, Moat N, de Belder MA, et al. Transcatheter aortic valve implantation in the United Kingdom: temporal trends, predictors of outcome, and 6-year followup: a report from the UK Transcatheter Aortic Valve Implantation (TAVI) Registry, 2007 to 2012. Circulation 2015;131:1181-90.

43. Mack MC, Szerlip M, Herbert MA, et al. Outcomes of Treatment of Nonagenarians With Severe Aortic Stenosis. Ann Thorac Surg 2015;100:74-80.

44. Mack MJ, Leon MB, Smith CR, et al. 5-year outcomes of transcatheter aortic valve replacement or surgical aortic valve replacement for high surgical risk patients with aortic stenosis (PARTNER 1): a randomised controlled trial. Lancet 2015;385:2477-84.

45. Poulin F, Yingchoncharoen T, Wilson WM, et al. Impact of Prosthesis-Patient Mismatch on Left Ventricular
Myocardial Mechanics After Transcatheter Aortic Valve Replacement. J Am Heart Assoc 2016;5:08.

46. Salizzoni S, D'Onofrio A, Agrifoglio M, et al. Early and mid-term outcomes of 1904 patients undergoing transcatheter balloon-expandable valve implantation in Italy: results from the Italian Transcatheter BalloonExpandable Valve Implantation Registry (ITER). Eur J Cardiothorac Surg 2016;50:1139-48.

47. Mayr NP, Michel J, Bleiziffer S, et al. Sedation or general anesthesia for transcatheter aortic valve implantation (TAVI). Journal of thoracic disease 2015;7:1518.

48. Svensson LG, Blackstone EH, Rajeswaran J, et al. Comprehensive analysis of mortality among patients undergoing TAVR: results of the PARTNER trial. J Am Coll Cardiol 2014;64:158-68.

49. Leon MB, Smith CR, Mack MJ, et al. Transcatheter or Surgical Aortic-Valve Replacement in Intermediate-Risk Patients. N Engl J Med 2016; 374:1609-20.

50. Adams DH, Popma JJ, Reardon MJ, et al. Transcatheter aortic-valve replacement with a self-expanding prosthesis. N Engl J Med 2014;370:1790-8.

51. Reardon MJ, Van Mieghem NM, Popma JJ, et al. Surgical or transcatheter aortic-valve replacement in intermediaterisk patients. N Engl J Med 2017;376:1321-31.

52. Søndergaard L, Steinbrüchel DA, Ihlemann N, et al. TwoYear Outcomes in Patients With Severe Aortic Valve Stenosis Randomized to Transcatheter Versus Surgical Aortic Valve Replacement: The All-Comers Nordic Aortic Valve Intervention Randomized Clinical Trial. Circ Cardiovasc Interv 2016;9.

53. Tamburino C, Barbanti M, D'Errigo P, et al. 1-year outcomes after transfemoral transcatheter or surgical aortic valve replacement: results from the Italian OBSERVANT study. J Am Coll Cardiol 2015;66:804-12.

54. Suradi HS, Hijazi ZM. TAVR update: Contemporary data from the UK TAVI and US TVT registries. Glob Cardiol Sci Pract 2015;2015:21.

55. Smith CR, Leon MB, Mack MJ, et al. Transcatheter versus surgical aortic-valve replacement in high-risk patients. $\mathrm{N}$ Engl J Med 2011;364:2187-98.

56. Kapadia SR, Leon MB, Makkar RR, et al. 5-year outcomes of transcatheter aortic valve replacement compared with standard treatment for patients with inoperable aortic stenosis (PARTNER 1): a randomised controlled trial. Lancet 2015;385:2485-91.

57. Leon MB, Piazza N, Nikolsky E, et al. Standardized endpoint definitions for transcatheter aortic valve implantation clinical trials: a consensus report from 
the Valve Academic Research Consortium. Eur Heart J 2011;32:205-17.

58. Deeb GM, Reardon MJ, Chetcuti S, et al. 3-Year Outcomes in High-Risk Patients Who Underwent Surgical or Transcatheter Aortic Valve Replacement. J Am Coll Cardiol 2016;67:2565-74.

59. Sulzenko J, Tousek P, Kocka V, et al. Transcatheter aortic valve implantation: long-term clinical outcome and valve durability. Expert review of medical devices 2015;12:529-35.

60. Sondergaard L. Time to Explore Transcatheter Aortic Valve Replacement in Younger, Low-Risk Patients. JACC Cardiovasc Interv 2016;9:2183-5.

61. Thyregod HG, Steinbrüchel DA, Ihlemann N, et al. Transcatheter versus surgical aortic valve replacement in patients with severe aortic valve stenosis: 1-year results from the all-comers NOTION randomized clinical trial. J Am Coll Cardiol 2015;65:2184-94.

62. Leon MB, Smith CR, Santarpino G, et al. Correspondence: Transcatheter Aortic-Valve Replacement- Leon et al. 2016 (PARTNER II). N Engl J Med 2016;375:699-701.

63. Clincialtrials.gov. Medtronic Transcatheter Aortic Valve Replacement in Low Risk Patients, NCT02701283. Clinicaltrials.gov. 2017. Available online: https:// clinicaltrials.gov/ct2/show/NCT02701283

64. Clinicaltrials.gov. The PARTNER 3 - Trial - The Safety and Effectiveness of the SAPIEN 3 Transcatheter Heart Valve in Low Risk Patients With Aortic StenosisNCT02675114, 2017. Available online: https:// clinicaltrials.gov/ct2/show/NCT02675114

65. Seiffert M, Diemert P, Koschyk D, et al. Transapical implantation of a second-generation transcatheter heart valve in patients with noncalcified aortic regurgitation. JACC Cardiovasc Interv 2013;6:590-7.

66. Roy DA, Schaefer U, Guetta V, et al. Transcatheter aortic valve implantation for pure severe native aortic valve regurgitation. J Am Coll Cardiol 2013;61:1577-84.

67. Morís C, Pascual I, Avanzas P. Will TAVI be the standard of care in the treatment of aortic stenosis? Rev Esp Cardiol (Engl Ed) 2016;69:1131-4.

68. Duncan A, Ludman P, Banya W, et al. Long-term outcomes after transcatheter aortic valve replacement in high-risk patients with severe aortic stenosis: the U.K. Transcatheter Aortic Valve Implantation Registry. JACC Cardiovasc Interv 2015;8:645-53.

69. Ludman PF, Moat N, de Belder MA, et al. Transcatheter aortic valve implantation in the UK: temporal trends, predictors of outcome and 6 year follow up: a report from the UK TAVI Registry 2007 to 2012. Circulation
2015;131:1181-90.

70. Brecker S, Mealing S, Padhiar A, et al. Cost-utility of transcatheter aortic valve implantation for inoperable patients with severe aortic stenosis treated by medical management: a UK cost-utility analysis based on patientlevel data from the ADVANCE study. Open Heart 2014;1:e000155.

71. Watt M, Mealing S, Eaton J, et al. Cost-effectiveness of transcatheter aortic valve replacement in patients ineligible for conventional aortic valve replacement. Heart 2012;98:370-6.

72. Murphy A, Fenwick E, Toff WD, et al. Transcatheter aortic valve implantation for severe aortic stenosis: the cost-effectiveness case for inoperable patients in the United Kingdom. Int J Technol Assess Health Care 2013;29:12-9.

73. Freeman PM, Protty MB, Aldalati O, et al. Severe symptomatic aortic stenosis: medical therapy and transcatheter aortic valve implantation (TAVI)-a realworld retrospective cohort analysis of outcomes and cost-effectiveness using national data. Open Heart 2016;3:e000414.

74. Armoiry X, Obadia JF, Iung B, et al. Clinical outcomes and direct costs after transcatheter aortic valve implantation in French centres: a longitudinal study of 1332 patients using a national database. Interact Cardiovasc Thorac Surg 2016;23:883-8.

75. Pellikka PA, Sarano ME, Nishimura RA, et al. Outcome of 622 adults with asymptomatic, hemodynamically significant aortic stenosis during prolonged follow-up. Circulation 2005;111:3290-5.

76. Tarantini G, Fovino LN, Gersh BJ. Transcatheter aortic valve implantation in lower-risk patients: what is the perspective? Eur Heart J 2017. [Epub ahead of print].

77. Wendt D, Osswald BR, Kayser K, et al. Society of Thoracic Surgeons score is superior to the EuroSCORE determining mortality in high risk patients undergoing isolated aortic valve replacement. Ann Thorac Surg 2009;88:468-74; discussion 474-5.

Cite this article as: Chakos A, Wilson-Smith A, Arora S, Nguyen TC, Dhoble A, Tarantini G, Thielmann M, Vavalle JP, Wendt D, Yan TD, Tian DH. Long term outcomes of transcatheter aortic valve implantation (TAVI): a systematic review of 5-year survival and beyond. Ann Cardiothorac Surg 2017;6(5):432-443. doi: 10.21037/acs.2017.09.10 


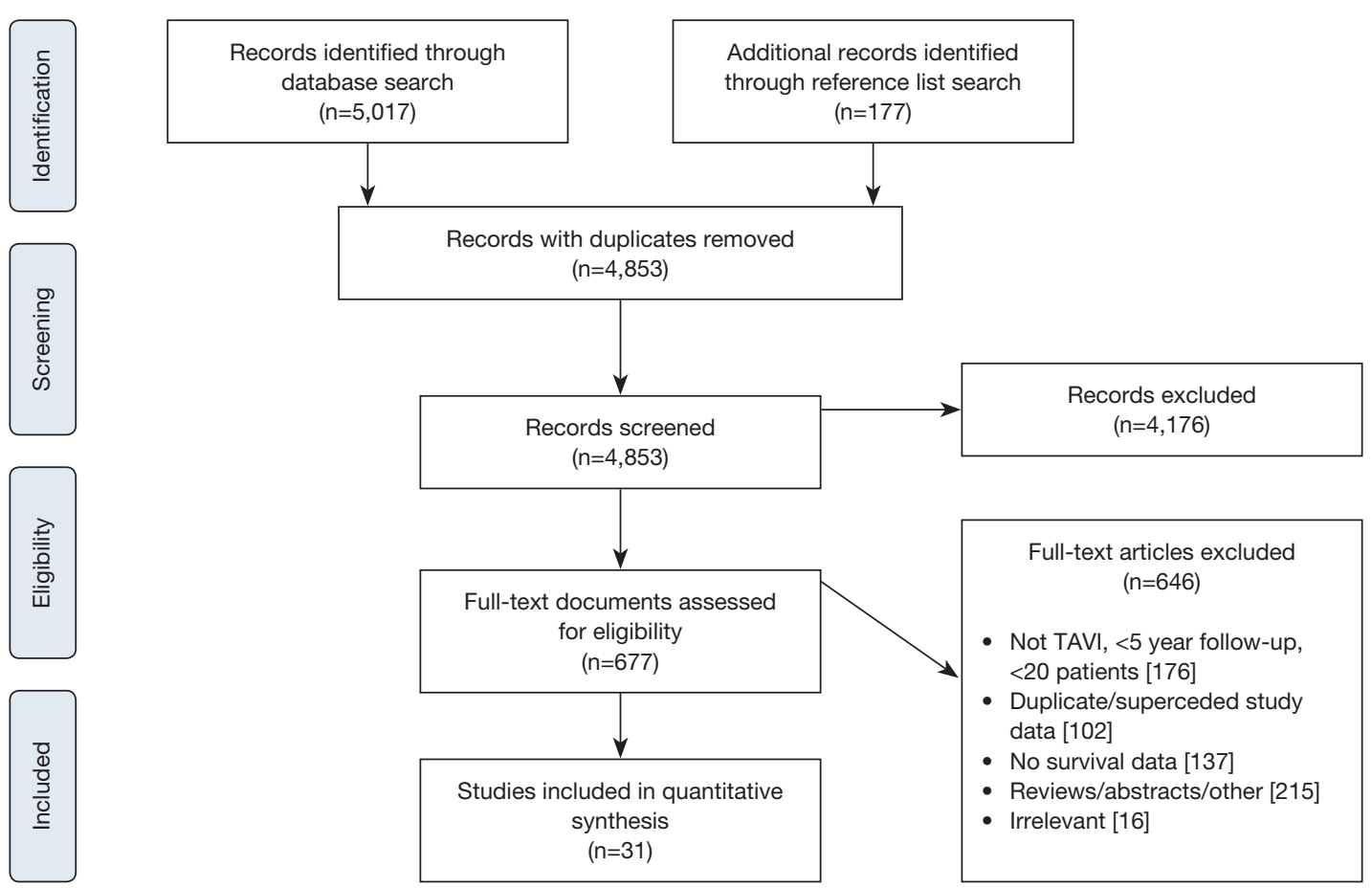

Figure S1 PRIMSA flow chart detailing the literature search process for TAVI outcomes at 5 years and beyond.

\begin{tabular}{|c|c|c|c|c|c|c|c|}
\hline Author & Year of publication & Country & Recruitment years & Patients (n) & Follow up (year) & Study design & IHE quality \\
\hline Barbanti & 2015 & Italy & 2007-2009 & 353 & 5 & $M C, P$ & M \\
\hline Barone-Rochette & 2014 & Belgium & 2005-2012 & 40 & 5 & SC, P, C & M \\
\hline Bouleti & 2017 & France & 2006-2010 & 253 & 6 & SC, P, C & $\mathrm{H}$ \\
\hline Brunner & 2017 & Canada & 2005-2014 & 133 & 6.5 & MC, $R$ & $\mathrm{~L}$ \\
\hline Buzzatti & 2017 & Italy & 2007-2015 & 558 & 7 & $\mathrm{SC}, \mathrm{R}$ & M \\
\hline Chen & 2016 & US & 2009-2013 & 60 & 6 & $\mathrm{SC}, \mathrm{R}$ & L \\
\hline Codner & 2015 & Israel & 2008-2015 & 360 & 5 & $\mathrm{SC}, \mathrm{P}$ & M \\
\hline D’Onofrio [1] & 2016 & Italy & $2007-2013$ & 338 & 6 & SC, R, C & M \\
\hline D’Onofrio [2] & 2016 & Italy & 2008-2015 & 44 & 5 & $\mathrm{MC}, \mathrm{P}$ & M \\
\hline Engborg & 2017 & Denmark & 2008-2012 & 128 & 6 & SC, R, C & M \\
\hline Escarcega & 2015 & US & 2007-2014 & 511 & 5 & SC, P, C & M \\
\hline Gotzmann & 2015 & Germany & 2008-2012 & 212 & 5 & $\mathrm{SC}, \mathrm{P}$ & M \\
\hline Huded & 2016 & US & 2008-2015 & 263 & 5 & $\mathrm{SC}, \mathrm{R}, \mathrm{C}$ & M \\
\hline Johansson & 2016 & Sweden & 2008-2014 & 166 & 6 & $\mathrm{SC}, \mathrm{R}, \mathrm{C}$ & $\mathrm{H}$ \\
\hline Logstrup & 2013 & Denmark & 2006-2010 & 81 & 5 & $\mathrm{SC}, \mathrm{R}$ & L \\
\hline Lopez-Aguilera & 2017 & Spain & 2008-2015 & 217 & 8 & $\mathrm{SC}, \mathrm{P}$ & M \\
\hline Ludman & 2015 & UK & 2007-2012 & 3,974 & 6 & $M C, R$ & $\mathrm{H}$ \\
\hline Mack [1] & 2015 & US & $2007-2013$ & 90 & 5 & $M C, R, C$ & M \\
\hline Mack [2] & 2015 & Canada, Germany, US & 2007-2009 & 348 & 5 & $\mathrm{RCT}, \mathrm{MC}, \mathrm{P}$ & $\mathrm{H}$ \\
\hline Munoz-Garcia & 2015 & Spain & 2008-2013 & 364 & 6 & SC & M \\
\hline Penkalla & 2015 & Germany & 2008-2013 & 593 & 5 & SC, P, C & M \\
\hline Pilgrim & 2015 & Switzerland & 2007-2010 & 257 & 5 & SC, P, C & M \\
\hline Poulin & 2016 & Canada, US & 2007-2013 & 102 & 5 & $\mathrm{MC}, \mathrm{R}$ & L \\
\hline Ruparelia & 2016 & Italy & 2007-2015 & 829 & 5 & $\mathrm{SC}, \mathrm{R}, \mathrm{C}$ & $M$ \\
\hline Salinas & 2016 & Spain & 2008-2012 & 79 & 5.5 & SC, P, C & $\mathrm{H}$ \\
\hline Salizzoni & 2016 & Italy & 2007-2012 & 1,904 & 5 & $\mathrm{MC}$ & $M$ \\
\hline Santarpino & 2015 & Germany & 2009-2013 & 364 & 5 & $\mathrm{SC}, \mathrm{R}$ & $\mathrm{L}$ \\
\hline Schymik & 2015 & Germany & 2008-2012 & 1,000 & 6 & SC, P, C & $\mathrm{H}$ \\
\hline Toggweiler & 2013 & Canada & 2005-2007 & 88 & 5.5 & $\mathrm{SC}, \mathrm{P}$ & $\mathrm{H}$ \\
\hline Unbehaun & 2014 & Germany & 2008-2013 & 104 & 5 & $\mathrm{SC}, \mathrm{R}, \mathrm{C}$ & M \\
\hline $\mathrm{Ye}$ & 2015 & Canada & $2007-2013$ & 42 & 7 & SC, P, C & M \\
\hline
\end{tabular}

IHE, Institute for Health Economics, Canada; SC, single-centre study; MC, multi-centre study; R, retrospective study; P, prospective study; C, consecutive patient recruitment. 


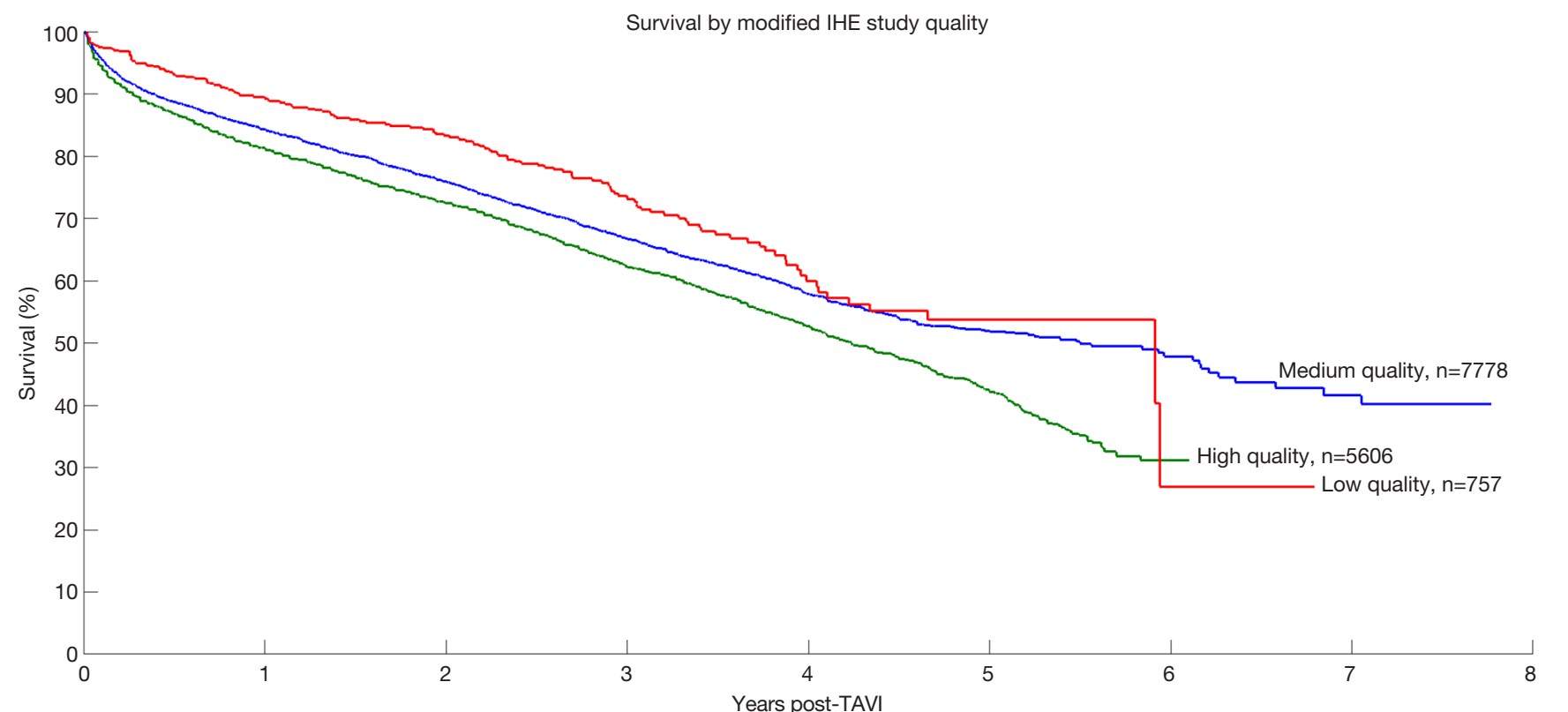

Figure S2 Survival of TAVI patients stratified by study quality according to our modified Canadian IHE guideline. IHE, Institute for Health Economics, Canada.

\begin{tabular}{|c|c|c|c|c|c|c|c|c|c|c|c|c|c|c|c|c|c|c|c|c|}
\hline \multirow{2}{*}{ Study (first author) } & \multirow{2}{*}{$\begin{array}{l}\text { Patient grouping (where } \\
\text { applicable) }\end{array}$} & \multirow{2}{*}{ Patients (n) } & \multirow{2}{*}{ Males } & \multirow{2}{*}{$\begin{array}{l}\text { Age, mean } \\
\pm \mathrm{SD} \text {, years }\end{array}$} & \multicolumn{4}{|c|}{ Patient risk scoring } & \multicolumn{12}{|c|}{ Risk factors } \\
\hline & & & & & STS & Logistic EuroSCORE & NYHA III, IV & Risk group ${ }^{1}$ & HTN & $\mathrm{DM}^{2}$ & $\mathrm{DL}$ & PVD & Pre-op LVEF (\%) & Pulmonary disease $^{3}$ & $\mathrm{Hx} \mathrm{CVA}^{4}$ & $\mathrm{H} \times \mathrm{CABG}$ & $\mathrm{HxPCl}{ }^{5}$ & $\mathrm{H} \times \mathrm{MI}$ & Renal $^{6}$ & $\mathrm{H} \times \mathrm{AF}$ \\
\hline Barbanti & $\mathrm{N} / \mathrm{A}$ & 353 & 157 & $81.5 \pm 6.3$ & $9.5 \pm 10$ & $19.5 \pm 11.9^{*}$ & 70 & $\mathrm{M} \wedge^{\wedge}$ & 267 & 107 & - & 96 & $50.6 \pm 12.3$ & 91 & 18 & 54 & 106 & 77 & 37 & 5 \\
\hline Bouleti & N/A & 253 & 136 & $81 \pm 8$ & $8 \pm 5.9$ & $23.3 \pm 14$ & 216 & H & 185 & 80 & 131 & 43 & $49.6 \pm 13.6$ & 90 & 20 & - & - & - & 8 & 102 \\
\hline \multirow[t]{2}{*}{ Brunner } & Low PVR & 61 & 38 & $80.4 \pm 8.5$ & - & - & - & - & - & - & - & - & - & 24 & - & - & - & - & - & - \\
\hline & High PVR & 72 & 33 & $80.3 \pm 8.3$ & - & - & - & - & - & - & - & - & - & 25 & - & - & - & - & - & - \\
\hline Buzzatti & No post-TAVI AR & 294 & 134 & $80.6 \pm 7.6$ & $6.4 \pm 4.7^{*}$ & $17.5 \pm 12.4^{*}$ & 18 & M & - & 95 & - & - & $53 \pm 13$ & 75 & 36 & - & - & - & 200 & - \\
\hline \multirow[t]{2}{*}{ Chen } & Improved LVEF & 30 & 18 & $81.5 \pm 8$ & $11.6 \pm 5.6$ & - & 30 & $\mathrm{H}$ & - & - & - & 11 & $35.2 \pm 6.5$ & 16 & 4 & 11 & 7 & 11 & - & 9 \\
\hline & Persistent poor LVEF & 30 & 21 & $81.5 \pm 6$ & $11.8 \pm 4.3$ & - & 30 & H & - & - & - & 11 & $39.2 \pm 5.9$ & 18 & 6 & 17 & 13 & 13 & - & 12 \\
\hline Codner & N/A & 360 & 157 & $82.1 \pm 6.9$ & $7.5 \pm 4.7$ & $19.5 \pm 11.2$ & 343 & M & 332 & 122 & 312 & 59 & - & 76 & 66 & 71 & 140 & 30 & - & 113 \\
\hline \multirow[t]{2}{*}{ D'Onofrio [1] } & TF TAVI & 233 & 126 & $80.5 \pm 7$ & - & $12.5 \pm 1.7$ & 166 & M & 209 & 62 & 139 & 13 & $54.9 \pm 12.9$ & 71 & 28 & - & 72 & 45 & 116 & 80 \\
\hline & TA TAVI & 105 & 55 & $80.2 \pm 6.1$ & - & $19.2 \pm 5.5$ & 72 & M & 97 & 29 & 71 & 20 & $55 \pm 10.9$ & 27 & 15 & - & 37 & 21 & 59 & 36 \\
\hline D'Onofrio [2] & Aortic valve & 44 & 25 & $77 \pm 10$ & $12.3 \pm 8$ & $28 \pm 16.6$ & 44 & $\mathrm{H}$ & 37 & 9 & - & 12 & $52 \pm 12.6$ & 11 & - & - & - & - & 4 & 8 \\
\hline \multirow[t]{2}{*}{ Engborg } & No PPM & 87 & 34 & $79.9 \pm 6$ & - & $17.9 \pm 12.5$ & 73 & M & 60 & 16 & 40 & - & $48.9 \pm 14$ & 21 & 8 & 13 & 18 & 16 & 11 & 19 \\
\hline & Post TAVI PPM & 41 & 24 & $82.1 \pm 4.2$ & - & $15.5 \pm 10.8$ & 35 & M & 27 & 7 & 20 & - & $53.4 \pm 11.5$ & 8 & 3 & 9 & 7 & 9 & 7 & 13 \\
\hline Escarcega & TF TAVI & 396 & 202 & $82 \pm 8$ & $9.2 \pm 4.4$ & - & - & $\mathrm{H}$ & 351 & 131 & 299 & 106 & $52 \pm 13$ & 115 & 53 & 123 & - & 74 & 195 & 159 \\
\hline Gotzmann & $\mathrm{N} / \mathrm{A}$ & 212 & 101 & $80 \pm 6$ & - & $22 \pm 16$ & 194 & H & - & - & - & - & $55 \pm 12$ & 212 & - & 32 & - & 46 & - & 73 \\
\hline \multirow[t]{2}{*}{ Huded } & CVD & 51 & 30 & $82.3 \pm 6.6$ & $8.7 \pm 3.7$ & - & - & $\mathrm{H}$ & 42 & 25 & 37 & 20 & $55 \pm 11$ & 15 & 9 & 30 & 7 & - & 16 & 25 \\
\hline & No CVD & 212 & 105 & $83.2 \pm 8.2$ & $8.7 \pm 4.5$ & - & - & $\mathrm{H}$ & 177 & 82 & 132 & 34 & $52 \pm 15$ & 62 & 21 & 67 & 25 & - & 63 & 83 \\
\hline Johansson & N/A & 166 & 85 & $80 \pm 9$ & - & $23 \pm 15$ & 35 & $\mathrm{H}$ & - & 40 & - & 86 & - & 29 & 13 & 81 & 52 & 17 & 11 & - \\
\hline Logstrup & TA TAVI & 59 & 26 & $80.1 \pm 6.83$ & - & $9.98 \pm 2.64^{\mathrm{a}}$ & 42 & - & 35 & 7 & - & - & - & - & - & 6 & 21 & 15 & - & - \\
\hline & TF TAVI & 22 & 11 & $82.2 \pm 7.29$ & - & $8.62 \pm 3.4^{a}$ & & - & 8 & 2 & - & - & - & - & - & & & 6 & - & - \\
\hline Lopez-Aguilera & PPM post-TAVI & 39 & 23 & $78 \pm 4$ & $10.7 \pm 8.4$ & $14.5 \pm 8.7$ & - & $\mathrm{M}^{\wedge}$ & 24 & 13 & 15 & - & $62 \pm 12.5$ & - & - & - & - & - & 5 & 9 \\
\hline & No PPM post-TAVI & 178 & 79 & $78 \pm 7$ & $11.6 \pm 10.5$ & $16 \pm 10$ & - & $\mathrm{M}^{\wedge}$ & 120 & 51 & 87 & - & $58 \pm 132$ & - & - & - & - & - & 20 & 45 \\
\hline Ludman & N/A & 3974 & 1883 & $81.3 \pm 7.6$ & - & $21.9 \pm 13.7$ & - & H & - & 866 & - & 1,025 & - & 892 & 325 & - & 851 & 892 & 268 & - \\
\hline Mack [1] & N/A & 90 & 46 & $91.81 \pm 1.79$ & $11.63 \pm 6.05$ & - & 80 & H & 80 & 18 & - & 31 & $53.1 \pm 11.7$ & 20 & 35 & 27 & - & 16 & 7 & - \\
\hline Mack [2] & N/A & 348 & 201 & $83.6 \pm 6.8$ & $11.8 \pm 3.3$ & $29.3 \pm 16.5$ & 328 & $\mathrm{H}$ & - & - & - & 148 & $52.5 \pm 13.5$ & 151 & 95 & 147 & 116 & 92 & 38 & 80 \\
\hline Munoz-Garcia & No AKI & 308 & 122 & $79.2 \pm 6.4$ & - & $18 \pm 11$ & 270 & M & 254 & 133 & 160 & 49 & $60.2 \pm 15$ & 109 & 36 & 25 & 87 & 52 & 68 & - \\
\hline & AKI & 58 & 28 & $79.9 \pm 4.5$ & - & $18.3 \pm 14$ & 49 & M & 47 & 17 & 29 & 12 & $61.7 \pm 13.4$ & 20 & 16 & 7 & 16 & 7 & 14 & - \\
\hline Penkalla & No CAD, no PCl & 285 & 83 & $79.6 \pm 6.67^{*}$ & $9.6 \pm 7.04^{*}$ & $26.3 \pm 17.3^{*}$ & $3.3 \pm 0.5$ & H & - & 61 & - & 161 & $55.4 \pm 10.1^{*}$ & - & 56 & 0 & - & - & - & 91 \\
\hline & $\begin{array}{l}\text { Non-significant CAD, } \\
\text { no PCl }\end{array}$ & 232 & 88 & $81 \pm 7.4^{*}$ & $11.6 \pm 9.3^{*}$ & $30.6 \pm 19.7^{*}$ & $3.3 \pm 0.5$ & H & - & 83 & - & 160 & $50.4 \pm 13.9^{*}$ & - & 59 & 0 & - & - & - & 70 \\
\hline & Significant CAD, PCl & 76 & 21 & $82.3 \pm 5.9^{*}$ & $12.6 \pm 8.4^{*}$ & $34.2 \pm 24.8^{*}$ & $3.4 \pm 0.5$ & $\mathrm{H}$ & - & 16 & - & 50 & $51.7 \pm 15.2^{\star}$ & - & 15 & 0 & - & - & - & 13 \\
\hline Ruparelia & TF TAVI & 703 & 281 & $83.3 \pm 7.5$ & $8.4 \pm 8.7$ & $21.6 \pm 16.2$ & - & H & 562 & 207 & 387 & 162 & - & 162 & 98 & 134 & 141 & 129 & 267 & 96 \\
\hline & Other access (OAS) & 126 & 64 & $78.7 \pm 24.2$ & $11.8 \pm 11.9$ & $28.5 \pm 19.5$ & - & H & 98 & 45 & 79 & 79 & - & 43 & 21 & 32 & 35 & 31 & 49 & 21 \\
\hline Salinas & N/A & 79 & 36 & $82.3 \pm 6.1$ & $5.9 \pm 2.9$ & $16.9 \pm 9.1$ & - & M & 63 & 33 & 38 & 10 & $55.4 \pm 11.8$ & 19 & 13 & 5 & 27 & 9 & 16 & 31 \\
\hline Salizzoni & N/A & 1904 & 757 & $81.7 \pm 6.2$ & $9.2 \pm 7.6$ & $21.1 \pm 13.7$ & 1,536 & H & 1,553 & 573 & - & 674 & $53.5 \pm 12.4$ & 468 & 171 & - & 267 & 371 & 152 & 414 \\
\hline Santarpino & N/A & 364 & 158 & $82 \pm 6$ & - & $26 \pm 17$ & $3.1 \pm 0.4$ & $\mathrm{H}$ & 339 & 207 & - & 98 & $54 \pm 14$ & 105 & - & - & - & - & 171 & - \\
\hline Schymik & TA TAVI & 413 & 202 & $81.5 \pm 5.8$ & - & $24.3 \pm 16.2$ & - & H & - & - & - & 91 & $55.8 \pm 5.8$ & 60 & 61 & - & - & 63 & 35 & - \\
\hline & TF TAVI & 587 & 233 & $82.1 \pm 5.1$ & - & $22.6 \pm 16.2$ & - & H & - & - & - & 64 & $57.5 \pm 14.1$ & 63 & 90 & - & - & 66 & 38 & - \\
\hline Toggweiler & N/A & 88 & 47 & $83 \pm 7$ & $9.3 \pm 5.0^{*}$ & - & - & $\mathrm{H}$ & 61 & 22 & - & - & $58.3 \pm 11.1^{*}$ & 23 & 14 & - & - & 69 & 47 & 45 \\
\hline Unbehaun & $\mathrm{N} / \mathrm{A}$ & 104 & 63 & $78.7 \pm 8.3^{*}$ & $17.7 \pm 12.0^{*}$ & $59.7 \pm 31.1^{*}$ & 68 & $\mathrm{H}$ & - & 34 & - & 72 & $25.0 \pm 7.5^{*}$ & - & 29 & 27 & 25 & - & 6 & 38 \\
\hline Ye & N/A & 42 & 28 & $80.5 \pm 9.8$ & $9.1 \pm 4.0^{*}$ & - & 39 & $\mathrm{H}$ & - & 10 & - & 13 & $56.5 \pm 13.8^{*}$ & 4 & 7 & 19 & - & - & 9 & - \\
\hline $\begin{array}{l}\text { *, these studies did I } \\
\text { risk group defined p } \\
\text { for the purposes of } \\
\text { "CVD (cerebrovascu } \\
\text { creatinines } 2 \mathrm{mg} / \mathrm{dl} \text {, } \\
\text { EurosCORE II classi } \\
\text { disease; Hx CVA, hi } \\
\text { TAVI, transcatheter z }\end{array}$ & 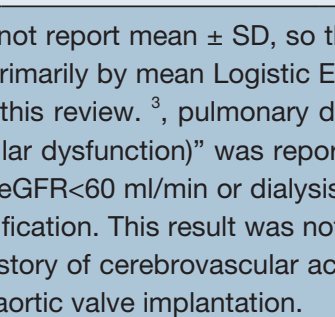 & $\begin{array}{l}\text { is/renal re } \\
\text { ot includec } \\
\text { cccident; }\end{array}$ & d he & $\begin{array}{l}\text { nere muttiple } \\
\text { I EurosCORE }\end{array}$ & $\begin{array}{l}y \text { the author } \\
\text { l) or } \geq 20 \text { (hig } \\
\text { pulmonary } \\
\text { Cl specificall } \\
\text { gories given } \\
\text { culation for t } \\
\text { tery bypass }\end{array}$ & $\begin{array}{l}\text { rs according to the met } \\
\text { gh risk: H). Where Logis } \\
\text { disease in general. Pulr } \\
\text { lly and those reporting } \\
\text { n (e.g., eGFR<60 mL/mi } \\
\text { the whole cohort. STS, } \\
\text { graft surgery; } \mathrm{Hx} \mathrm{PCl,}\end{array}$ & $\begin{array}{l}\text { In and dalys } \\
\text { Society of } T\end{array}$ & Wan e & risk sc & $\begin{array}{l}\text { sumc } \\
\text {; NYH }\end{array}$ & ex & weer & $\begin{array}{l}\text { ogstruu et al. } \\
\text { scciation functi }\end{array}$ & $\begin{array}{l}\text { rd 15) report EuroSCC } \\
\text { group; HTN, hyperten }\end{array}$ & $\begin{array}{l}\text { REE but } \\
\text { sion; DM }\end{array}$ & $\begin{array}{l}\text { ot specify wit } \\
\text { abetes mellith }\end{array}$ & 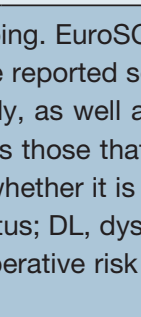 & coidaer & $\begin{array}{l}\text { g tak } \\
\text { weri } \\
\text { rologi }\end{array}$ & $\begin{array}{l}\text { cedence. } \\
\text { ed togethe } \\
\text { sunction" } \\
\text { LuE criteria } \\
\text { logistic o } \\
\text { al vascula } \\
\text { risk group }\end{array}$ \\
\hline
\end{tabular}


Table S3 Patient operative details and outcomes

\begin{tabular}{|c|c|c|c|c|c|c|c|c|c|c|c|c|c|c|}
\hline \multirow{2}{*}{ Study (first author) } & \multirow{2}{*}{ Patient grouping (where applicable) } & \multirow{2}{*}{ Patients $(n)$} & \multicolumn{3}{|c|}{ Valve type $^{1}$} & \multicolumn{5}{|c|}{ TAVI approach } & \multicolumn{4}{|c|}{ Procedural outcomes } \\
\hline & & & Edwards & Medtronic & Other & TF & TA & TSub & TAortic & Other & PPM implant & $\left.A K\right|^{2}$ & 30-day stroke/CVA ${ }^{3}$ & 30-day mortality ${ }^{4}$ \\
\hline Barbanti & $n / a$ & 353 & 0 & 353 & 0 & 317 & - & 36 & - & - & 75 & 89 & 8 & 23 \\
\hline Barone-Rochette & $n / a$ & 40 & 40 & 0 & 0 & 25 & 15 & - & - & - & - & - & - & 10 \\
\hline Bouleti & $n / a$ & 253 & 186 & 67 & 0 & 171 & 82 & - & - & - & 36 & 1 & 10 & 27 \\
\hline \multirow[t]{2}{*}{ Brunner } & Low PVR & 61 & - & - & - & - & - & - & - & - & - & - & - & - \\
\hline & High PVR & 72 & - & - & - & - & - & - & - & - & - & - & - & - \\
\hline \multirow[t]{2}{*}{ Buzzatti } & No post-TAVI AR & 294 & 137 & 76 & 81 & 251 & 25 & 14 & 4 & - & - & - & - & 21 \\
\hline & Mild AR post-TAVI & 264 & 128 & 90 & 46 & 236 & 12 & 14 & 2 & - & - & - & - & \\
\hline \multirow[t]{2}{*}{ Chen } & Improved LVEF & 30 & 30 & 0 & 0 & M & M & 0 & 0 & 0 & - & - & - & - \\
\hline & Persistent poor LVEF & 30 & 30 & 0 & 0 & M & M & 0 & 0 & 0 & - & - & - & - \\
\hline Codner & $n / a$ & 360 & 97 & 258 & 5 & 308 & 31 & 19 & 1 & 1 & 58 & 59 & - & 14 \\
\hline \multirow[t]{2}{*}{ D'Onofrio [1] } & TF TAVI & 233 & 255 & 83 & - & 233 & - & - & - & - & 66 & 35 & 7 & 11 \\
\hline & TA TAVI & 105 & & & - & - & 105 & - & - & - & 11 & 39 & 3 & 4 \\
\hline D'Onofrio [2] & Aortic valve & 44 & 32 & 12 & 0 & 28 & 16 & 0 & 0 & 0 & 0 & 1 & 0 & 2 \\
\hline \multirow[t]{2}{*}{ Engborg } & No PPM & 87 & 25 & 62 & - & - & - & 4 & - & - & 0 & - & - & 3 \\
\hline & Post TAVI PPM & 41 & 3 & 38 & - & - & - & 2 & - & - & 41 & - & - & 1 \\
\hline \multirow[t]{2}{*}{ Escarcega } & TA TAVI & 115 & - & - & - & - & 115 & & - & - & 4 & 36 & 5 & 22 \\
\hline & TF TAVI & 396 & - & - & - & 396 & - & & - & - & 34 & 52 & 21 & 17 \\
\hline Gotzmann & $n / a$ & 212 & 43 & 169 & - & 164 & - & 5 & - & - & - & - & - & 11 \\
\hline \multirow[t]{2}{*}{ Huded } & CVD & 51 & - & - & - & 28 & 18 & . & 5 & - & - & - & 0 & 2 \\
\hline & No CVD & 212 & - & - & - & 163 & 37 & - & 11 & - & - & - & 18 & 441 \\
\hline Johansson & $n / a$ & 166 & 168 & 0 & 19 & 76 & 92 & - & - & - & 15 & 7 & 5 & 7 \\
\hline \multirow[t]{2}{*}{ Logstrup } & TA TAVI & 59 & 59 & - & - & - & 59 & - & - & - & - & - & - & - \\
\hline & TF TAVI & 22 & 22 & - & - & 22 & - & - & - & - & - & - & - & \\
\hline \multirow[t]{2}{*}{ Lopez-Aguilera } & PPM post-TAVI & 39 & - & 39 & - & - & - & - & - & - & 39 & - & - & 14 \\
\hline & No PPM post-TAVI & 178 & - & 178 & - & - & - & - & - & - & 0 & - & - & \\
\hline Ludman & $n / a$ & 3974 & 2036 & 1897 & 41 & 2828 & 761 & 190 & 196 & - & 672 & - & 99 & 231 \\
\hline Mack [1] & $n / a$ & 90 & 86 & 4 & - & - & - & - & - & - & - & 7 & 2 & 10 \\
\hline Mack [2] & $n / a$ & 348 & 348 & - & - & 244 & 104 & - & - & - & 13 & 4 & 19 & 12 \\
\hline \multirow[t]{2}{*}{ Munoz-Garcia } & No AKI & 308 & - & 308 & - & 277 & - & 30 & 1 & - & 71 & 0 & - & 4 \\
\hline & AKI & 58 & - & 58 & - & 49 & - & 8 & 1 & - & 20 & 58 & - & 8 \\
\hline \multirow[t]{3}{*}{ Penkalla } & No CAD, no PCl & 285 & 285 & - & - & - & 285 & - & - & - & - & 42 & - & 15 \\
\hline & Non-significant CAD, no PCl & 232 & 232 & - & - & - & 232 & - & - & - & - & 34 & - & 9 \\
\hline & Significant CAD, PCl & 76 & 76 & - & - & - & 76 & - & - & - & - & 11 & - & 2 \\
\hline Pilgrim & $n / a$ & 257 & Mixed & Mixed & - & M & M & M & - & - & 60 & 43 & 10 & 17 \\
\hline \multirow[t]{2}{*}{ Poulin } & No PPM & 61 & 52 & 9 & - & 27 & 34 & - & - & - & - & - & - & - \\
\hline & PPM post-TAVI & 41 & 38 & 3 & - & 23 & 18 & - & - & - & - & - & - & - \\
\hline Ruparelia & TF TAVI & 703 & - & - & - & 703 & - & - & - & - & 68 & 166 & 12 & 29 \\
\hline & Other access (OAS) & 126 & - & - & - & - & - & - & - & - & & & & \\
\hline Salinas & n/a & 79 & 79 & - & - & 64 & 15 & - & - & - & 3 & 14 & 2 & 10 \\
\hline Salizzoni & $\mathrm{n} / \mathrm{a}$ & 1,904 & 1,904 & - & - & 1,252 & 630 & 4 & 18 & - & 116 & 155 & 54 & 37 \\
\hline Santarpino & $\mathrm{n} / \mathrm{a}$ & 364 & 94 & Mixed & Mixed & 205 & 158 & - & 1 & - & 9 & 1 & 5 & 3 \\
\hline Schymik & TA TAVI & 413 & 402 & - & 11 & - & 413 & - & - & - & 44 & 145 & 7 & 25 \\
\hline & TF TAVI & 587 & 399 & 188 & - & 587 & - & - & - & - & 92 & 117 & 14 & 38 \\
\hline Toggweiler & $n / a$ & 88 & 88 & - & - & 64 & 24 & - & - & - & 6 & 1 & 1 & 0 \\
\hline Unbehaun & $n / a$ & 104 & 104 & - & - & - & 104 & - & - & - & 6 & 26 & 2 & 6 \\
\hline Ye & $\mathrm{n} / \mathrm{a}$ & 42 & 42 & - & - & M & M & - & - & - & 0 & 1 & 0 & 1 \\
\hline
\end{tabular}

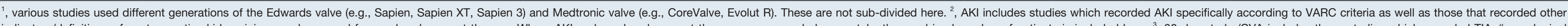

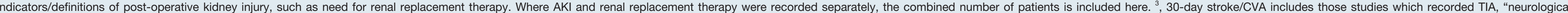

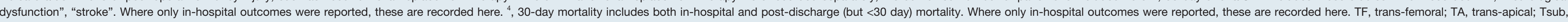
trans-subclavian; TAortic, trans-aortic; PPM, permanent pacemaker implant; AKI, acute kidney injury; CVA, cerebrovascular accident. M; mixed valve types, operative approaches used between those categories marked with "M".

References

78. Wan X, Wang W, Liu J, et al. Estimating the sample mean and standard deviation from the sample size, median, range and/or interquartile range. BMC Med Res Methodol 2014;14:135. 